\title{
Solar Elastotic Bands of the Forearm: An Extremely Rare Presentation
}

\author{
Anup Kumar Tiwary ${ }^{1,}$ and Piyush Kumar ${ }^{2}$ \\ ${ }^{1}$ Department of Dermatology, Subharti Medical College, Meerut, India \\ ${ }^{2}$ Department of Dermatology, Katihar Medical College, Katihar, India \\ "Corresponding author: Department of Dermatology, Subharti Medical College, Meerut, India. Email: anup07tunnu07@gmail.com
}

Received 2019 November 27; Revised 2020 January 06; Accepted 2020 January 16.

Keywords: Solar, Elastotic Bands, Senile, Actinic

\section{Dear Editor,}

A 56-year-old Indian female with skin Fitzpatrick type$V$ is presented with erythematous nodules and plaques on her upper extremities for the past two years. The lesions were asymptomatic and progressive. She had an occupational history of long-term exposure to sunlight. No other cutaneous areas had similar skin lesions.

The local cutaneous examination revealed hyperpigmentation and slightly erythematous, edematous, and smooth papulonodular lesions on the extensor surface of both her forearms. These lesions were coalescing into plaques, giving a mammillated appearance and some of them were seen to be arranged in irregular cord-like bands (Extension Extension to the medial and lateral sides of forearms were observed. The purpuric macules were also present. General and systemic examination were unremarkable. Routine laboratory parameters were also within normal limits.

Histopathologic examination (HPE) on Hematoxylin and Eosin (H \& E) staining revealed epidermal atrophy with effacement of the rete ridges. Dermis showed cleftlike spaces and bundles of degenerated elastic fibers composed of basophilic, granular materials in the dermis (Figure $2 \mathrm{~A}$ and $\mathrm{B}$ ). Spindle-shaped fibroblasts were seen along with mild perivascular lymphocytic infiltrates. Verhoeff Van-Gieson staining and electron microscopic studies could not be done due to the limited resources of the institution.

Although, elastotic changes in the skin of forearm are rarely reported, the histopathological findings were consistent with the diagnosis of solar elastosis. Therefore, we concluded with the diagnosis of solar elastotic bands of the forearm.

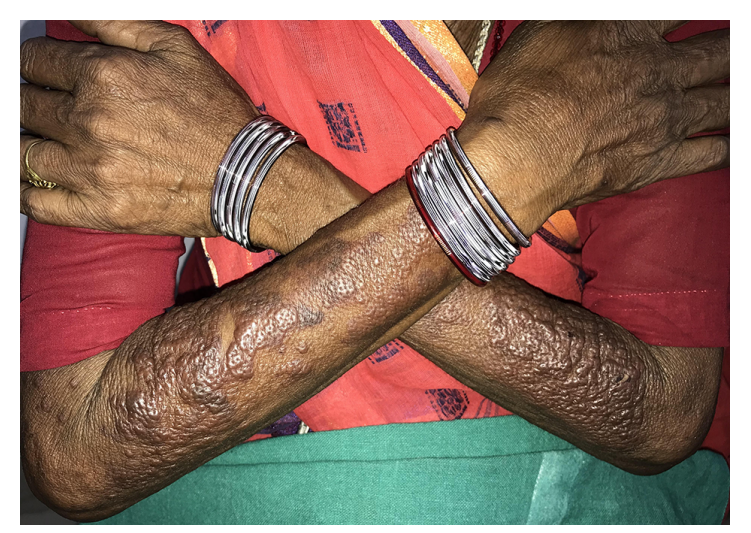

Figure 1. Mammillated skin with smooth papules and nodules coalescing into plaques arranged in band-like fashion on both forearm

Solar elastosis is a pathological hallmark of photoageing, often seen as deposition of abnormal, amorphous granular materials within the dermis (1). Although, the exact origin of such materials is not determined, it has been attributed to both the degeneration of elastin fibers caused by chronic exposure of ultraviolet A rays and synthesis of abnormal elastin fibers by photodamaged fibroblasts (1). It leads to peculiar cutaneous changes such as hyperpigmentation, atrophy, thickening, telangiectasia, purpura, coarsening, wrinkling, and poikiloderma. It may also lead to development of some skin lesions, most commonly colloid milium, cutis rhomboidalis nuchae, FavreRacouchot syndrome, elastotic striae, papular elastosis and anetoderma, and less commonly as acrokeratoelastoidosis of marginalis, elastosis linearis rubra nasi, upper and mid dermal elastolysis.

Of note, "Solar elastotic bands of forearm" is an ex-

Copyright (C) 2020, Journal of Skin and Stem Cell. This is an open-access article distributed under the terms of the Creative Commons Attribution-NonCommercial 4.0 International License (http://creativecommons.org/licenses/by-nc/4.0/) which permits copy and redistribute the material just in noncommercial usages, provided the original work is properly cited. 

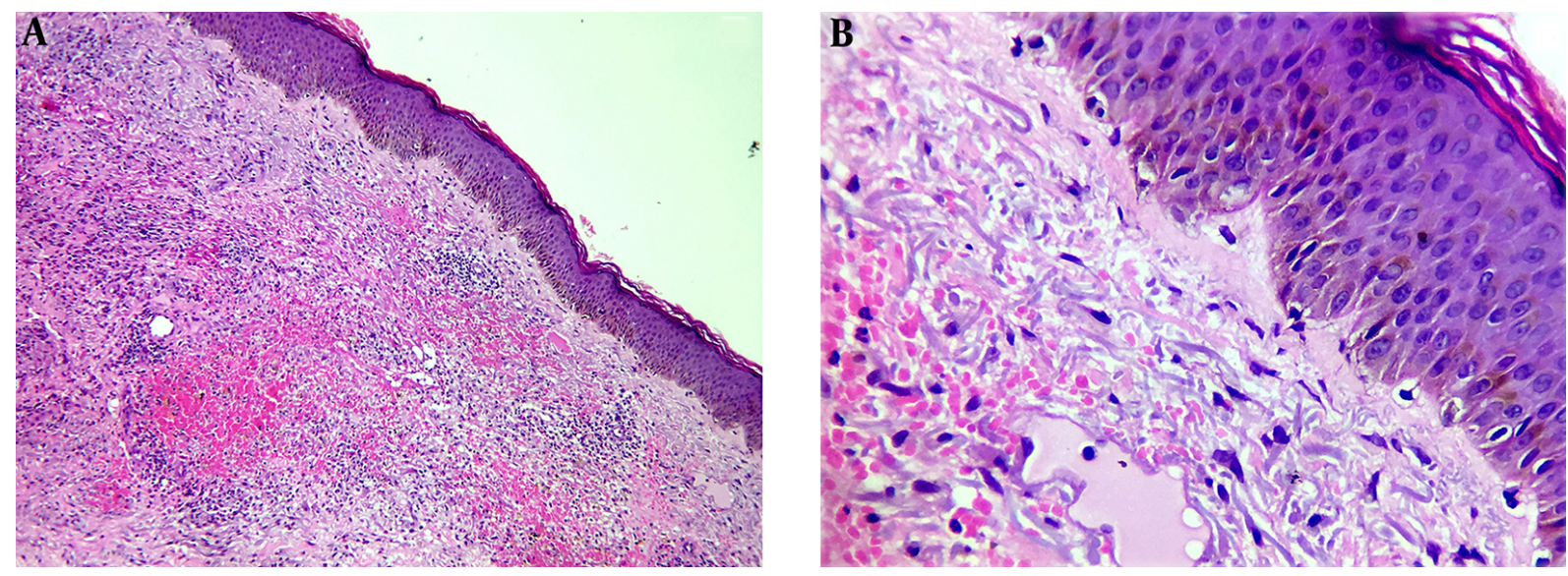

Figure 2. A, Effacement of the rete ridges with superficial mild perivascular lymphocytic infiltrates and dermal cleft-like spaces in dermis (hematoxylin and eosin, original magnification $10 \times$ ); B, bundles of degenerated basophilic fibrilar elastic fibres in the dermis along with some spindles fibroblasts around cleft like spaces (hematoxylin and eosin, original magnification $40 \times$ )

tremely rare presentation of solar elastosis, which was coined and first described by Raimer et al. (1), in 1986 in his three Caucasian patients. Over the years, three more cases with similar clinical and histologic features were reported. The details of the clinical profile of previous cases have been summarized in Table 1(2-4). In the most recent case, the role of sun exposure was denied probably based on the absence of history of long term sun exposure and involvement of only right forearm, although cutaneous signs of actinic damage such as senile purpura, atrophy, and coarsening of skin as well as histopathological changes were all in favor of solar elastosis (4).

Solar elastotic bands characteristically appear on the forearm/s presenting as mostly asymptomatic, skin colored or yellowish, papules, and nodules merging to form plaques and cord-like bands (1). The classical histopathology on $\mathrm{H} \& \mathrm{E}$ staining shows normal or atrophic epidermis with effaced rete ridges. The dermis shows large nodular collections composed of abnormal amorphous and basophilic elastic fibrils and cleft-like spaces (4). Staining with Verhoeff-van-Gieson can be done to see the thick and serpiginous bundles of elastic fibers. A mild perivascular lymphocytic infiltrates and spindled fibroblasts are seen in opposition to the elastotic fibers. Capillary dilatation may also be observed with some hemorrhagic foci in papillary dermis.

The cutaneous amyloidosis and focal mucinoses are usually considered as differential diagnosis. The histopathologic examination with proper staining can easily rule out these entities (1). Congo red staining can be done to show the amyloid deposits, which gives apple-green birefringence under polarized light. Mucin deposition can be stained by alcian blue, mucicarmine, or PAS. The elastotic lesions are usually persisting and recalcitrant to keratolytics, and do not vanish over time even with photoprotection (3).

Solar elastotic bands of the forearm is a rare presentation of actinic elastosis, with very few cases reported in English literature. The involvement of atypical sites with characteristic histopathological features of elastosis warrant the need of HPE in all cases, irrespective of pattern of involvement.

\section{Footnotes}

Authors' Contribution: Study concept and design: Piyush Kumar and Anup Kumar Tiwary. Analysis and interpretation of data: Anup Kumar Tiwary and Piyush Kumar. Drafting of the manuscript: Anup Kumar Tiwary. Critical revision of the manuscript for important intellectual content: Piyush Kumar and Anup Kumar Tiwary. Statistical analysis: Anup Kumar Tiwary.

Conflict of Interests: There is no conflict of interest. Funding/Support: No funding or support. 


\begin{tabular}{|c|c|c|c|c|c|c|c|c|}
\hline $\begin{array}{l}\text { Serial } \\
\text { Number of } \\
\text { Cases }\end{array}$ & Author & Year & Age, $y$ & Gender & Race & Site/s & $\begin{array}{l}\text { History of Chronic } \\
\text { Sun Exposure }\end{array}$ & $\begin{array}{c}\text { Sign/s of Actinic } \\
\text { Damage (Actinic } \\
\text { Purpura, Atrophy) }\end{array}$ \\
\hline 01 & Raimer et al. (1) & 1986 & 83 & Female & Caucasian & $\begin{array}{l}\text { Flexors of both } \\
\text { forearms }\end{array}$ & Present & Present \\
\hline 02 & Raimer et al. (1) & 1986 & 63 & Male & Caucasian & $\begin{array}{l}\text { Flexors of both } \\
\text { forearms }\end{array}$ & Present & Present \\
\hline 03 & Raimer et al. (1) & 1986 & 71 & Male & Caucasian & $\begin{array}{l}\text { Flexors of both } \\
\text { forearms }\end{array}$ & Present & Present \\
\hline 04 & $\begin{array}{l}\text { Stanford et al. } \\
\text { (2) }\end{array}$ & 1995 & 43 & Female & Caucasian & $\begin{array}{l}\text { Extensor of } \\
\text { right forearm }\end{array}$ & Present & Present \\
\hline 05 & $\begin{array}{l}\text { Kiyohara et al. } \\
\text { (3) }\end{array}$ & 2003 & 68 & Male & Japanese & $\begin{array}{c}\text { Flexural } \\
\text { surface of } \\
\text { forearm, } \\
\text { shoulder and } \\
\text { chest }\end{array}$ & Present & Present \\
\hline 06 & Haga et al. (4) & 2015 & 57 & Female & Japanese & $\begin{array}{l}\text { Extensor of } \\
\text { right forearm }\end{array}$ & Absent & Present \\
\hline 07 & Our case & 2018 & 56 & Female & $\begin{array}{c}\text { Caucasoid } \\
\text { (Indian) }\end{array}$ & $\begin{array}{l}\text { Extensors of } \\
\text { both forearms }\end{array}$ & Present & Present \\
\hline
\end{tabular}

\section{References}

1. Raimer SS, Sanchez RL, Hubler WR, Jr, Dodson RF. Solar elastotic bands of the forearm: An unusual clinical presentation of actinic elastosis.J Am Acad Dermatol. 1986;15(4 Pt 1):650-6. doi: 10.1016/s01909622(86)70220-x. [PubMed: 3771841].

2. Stanford DG, Georgouras KE, Killingsworth M. Raimer's bands: Case report with a review of solar elastosis. Acta Derm Venereol.
1995;75(5):372-4. doi: 10.2340/0001555575372374. [PubMed: 8615055].

3. Kiyohara T, Kumakiri M, Kouraba S. Solar elastotic bands in a Japanese man. J Am Acad Dermatol. 2003;49(6):1193-5. doi: 10.1016/s01909622(03)00848-x. [PubMed: 14639421].

4. Haga N, Abe R, Morita Y, Fujimura Y, Natsuga K, Nomura T, et al. Non-solar-induced elastotic bands on the forearm. Eur J Dermatol. 2015;25(5):508-9. doi: 10.1684/ejd.2015.2629. [PubMed: 26394922]. 